EESTI NSV TEADUSTE AKADEEMIA TOIMETISED 1952. 1 k. nr. 3 ИЗВЕСТИЯ АКАДЕМИИ НАУК ЭСТОНСКОИ ССР 1952. ТоМ I, № 3

\title{
МЕТОДИКА ФЛЮОРЕСЦЕНТНОГО СПЕКТРАЛЬНОГО АНАЛИЗА НЕКОТОРЫХ АРОМАТИЧЕСКИХ УГЛЕВОДОРОДОВ
}

\author{
Н. М. ТОМСОН, \\ действительный член Академии Наук Эстонской ССР
}

Қанцерогенные вещества, относящиеся к многоядерным ароматическим углеводородам, обладают способностью испускать флюоресцентный свет в синефиолетовой области спектра под действием падающих на них ультрафиолетовых лучей. Это свойство позволило обнаруживать их в смеси других органических соединений без выделения, например в жидких продуктах сухой перегонки сланцев и в смолистых веществах, выделенных из дыма и сажи, - продуктов неполного сгорания сланцев, каменного угля, торфа, дров и бензина (выхлопные газы).

Наиболее часто среди других углеводородов встречается 3, 4-бензпирен, обнаруженный в вышеупомянутых объектах посредством описываемой методики. Бензпирен дает главные полосы поглощения в синефнолетовой области спектра 4045, 4100, 4281 и $4550 \AA$. В этой же области на близких длинах волн флюоресцируют и другие ароматические углеводороды, например $3,4,8,9$-дибензпирен, $1,2,5,6$-дибензантрацен и некоторые другие, встречающиеся реже бензпирена.

Метод флюоресцентного спектрального анализа на стеклянном спектрографе был опубликован в 1948 году Э. В. Шпольским, А. А. Ильиной и В. В. Базилевичем* и является наилучшим. Однако стеклянный спектрограф встречается весьма редко и поэтому метод мало доступен. Ультрафиолетовые спектрографы имеются в каждой спектральной лаборатории. Для расширения возможности применения анализа канцерогенных углеводородов был разработан** метод для ультрафиолетового спектрографа УСП-І с сильвиновой призмой, выпущенного Ленинградским оптикомеханическим заводом в 1939 году. Этот спектрограф рассчитан на длины волн от 2100 до $4000 \AA$, тогда как полосы поглощения 3, 4-бензпирена находятся в области 4045-4550 А, т. е. за пределами расчетной длины волны. Тем не менее на краю пластинки остается место около 7 мм, где помещаются спектральные линии длиною волны выше $4000 \AA$ при значительно меньшей дисперсии, но все-таки достаточной для целей анализа. Ультрафиолетовый спектрограф ИСП-22 является более удобным, так как полосы поглоцения бензпирена занимают место около 15 мм***.

Полосы поглощения в флюоресцентном спектре зависят от структуры молекулы определяемого вещества, и при изменении молекулы хотя бы

* Известия АН СССР, № 5, 1948.

** В Институте общей и коммунальной гигиены АМН СССР.

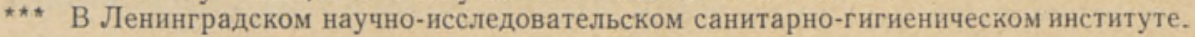


на один атом изменяется и спектр, что указывает на строгую специфичность анализа.

Источником ультрафиолетового света для возбуждения флюоресценции канцерогенных углеводородов служит кварцевая лампа ПРК-4. Кварцевая лампа располагается под углом $30^{\circ}$ к оптической оси спектрографа, на расстоянии 60 см от кюветы, на уровне щели спектрографа. Қварцевая лампа закрывается светонепроницаемой коробкой с трубкой длиною около 30 см, в конце которой укрепляется кварцевая сферическая линза диаметром в 35 мм и фокусным расстоянием в 160 мм. Непосредственно перед кварцевой линзой располагается ультрафиолетовый фильтр (кобальт-никелевое стекло) на расстоянии около 30 см от кюветы. Флюоресцентный свет от кюветы с исследуемой пробой фокусируется на щели спектрографа (посредством кварцевой цилиндрической линзы диаметром в 35 мм и фокусным расстоянием в 160 мм) в виде узкой полосы шириною около 2 мм. Последняя линза ставится на расстоянии 22 см от щели и 44 см от кюветы. Комната, в которой производится анализ, должна быть затемнена. Позади кюветы ставится поглотитель света в виде коробки с окошечком, оклеенной изнутри и снаружи черной бумагой, черным бархатом или закопченной. Лучи, попадающие на черные поверхности коробки, поглощаются, и окошечко поглотителя почти не отражает света. Размер коробки $8 \times 8 \times 8 \mathrm{~cm}$, размер окошечка $3 \times 4$ см.

Вместо кварцевых линз могут применяться и стеклянные линзы, поскольку как возбуждающая линия ртути 3663, так и флюоресцентный свет находятся в видимой области спектра.

Плоско-параллельная кварцевая кювета должна быть высотою в 4 см, шириною не менее 1 см и глубиною в передне-заднем направлении от 1 до 5 мм. Вместо кварцевых кювет могут применяться также и стеклянные кюветы, состоящие из двух плоских стеклянных пластинок и прокладки у-образной формы, выпиленной из прозрачной пластмассы или согнутой из стеклянной палочки с отшлифованными сторонами для приклеивания пластинок. Задняя пластинка может быть из толстого стекла (2,0 мм), а передняя из тонкого стекла (0,2 мм). В случае кварцевой кюветы, из кварца должна быть только передняя пластинка, Склеивание кюветы производится парафином или менделеевской замазкой. В крайнем случае вместо плоско-параллельных кювет могут применяться стеклянные пробирки внешним диаметром в 10 мм и внутренним диаметром в 8 мм для пробы в количестве 2,5 куб. см. В случае применения пробирок существует опасность попадания отраженного от цилиндрических стенок пробирки света в спектрограф, что усиливает линии ртути в спектре; для избежания этого необходимо пробирку ставить не строго вертикально, а с наклоном в $2-3^{2}$. При наклонном положении отраженные от пробирки лучи уйдут в сторону и в спектрограф не попадут.

Вместо кювет можно применять смазывание предметного стекла пробой, разведенной в вазелиновом масле йли в белом вазелине. В этом случае проба непосредственно отражает лучи в спектрограф, а не через прозрачные пластинки. Вазелиновое масло нетрудно найти почти совсем не флюоресцирующее, тогда как белый вазелин флюоресцирует голубым светом более сильно. При проверке спектра флюоресценции от вазелина полос бензпирена в нем не оказалось, тем не менее равномерное свечение от вазелина несколько уменьшает интенсивность полос поглощения бензпирена в той же, примерно, области.

Наводка на фокус производится без ультрафиолетового фильтра. Резкое изображение трубки кварцевой лампы шириною около 6 мм фокусируется на кювете, а изображение кюветы фокусируется на щели спектрографа в виде полоски шириною в 2 мм. Правильность фокусировки кон- 
тролируется также визуально в кассетной части спектрографа по заполнению светом объектива.

Ширина щели спектрографа бралась в 0,1 мм; при высоких концентрациях (сотые доли процента) достаточно брать ширину щели в 0,05 мм, а при малых концентрациях (тысячные доли процента) - в 0,2 мм. Светосила ультрафиолетового спектрографа равняется $1: 12$, тогда как стеклянный спектрограф имеет светосилу 1:4,5. Следовательно, экспозиция на ультрафиолетовом спектрографе должна быть больше. Экспозиция колеблется в пределах от 1 до 15 минут. Съемка спектров производится через диафрагму с тремя ступеньками таким образом, чтобы при 15-минутной общей экспозиции получить три спектра с экспозицией в 5, 10 и 15 минут. Так как концентрация прямо пропорциональна интенсивности почернения фотопластинки, а интенсивность почернения пропорциональна экспозиции, то три ступеньки почернения спектра, снятые через ступенчатую диафрагму при съемке спектра известной концентрации бензпирена, например, $0,01 \%$, могут служить для оценки концентрации при сравнении со спектрами проб с неизвестной концентрацией. Так, например, интенсивность почернения при пятиминутной экспозиции будет соответствовать $0,0033 \%$, при десятиминутной экспозиции - $0,0066 \%$, и при 15 -минутной экспозиции - $0,008 \%$. Стандартный раствор чистого бензпирена должен делаться с добавлением смолы, не содержащей бензпирена, для того чтобы общее диффузное почернение спектра соответствовало условиям съемки спектра пробы.

Количественный анализ бензпирена можно вести путем измерения фотометром интенсивности флюоресцентного света.

Для оценки концентрации может быть использован ступенчатый ослабитель, состоящий из кварцевой пластинки, на которую нанесены слои платины различной прозрачности путем катодного распыления на семи ступеньках, через который снимается спектр (см. табл. 1).

Т аб ли ц а 1

Вычисление концентрации при помощи платинового ступенчатого ослабителя

\begin{tabular}{c|c|c}
\hline $\begin{array}{c}\text { Соотношение } \\
\text { интенсивностей } \\
\text { на 7 ступеньках }\end{array}$ & $\begin{array}{c}\text { Процент } \\
\text { ослабления }\end{array}$ & $\begin{array}{c}\text { Изменение концентра- } \\
\text { ции при стандартном } \\
\text { растворе в 0,01\% }\end{array}$ \\
\hline & & \\
0,977 & 100 & 0,00 \\
0,853 & 87,2 & 0,00872 \\
0,719 & 73,5 & 0,00735 \\
0,582 & 59,5 & 0,00595 \\
0,443 & 45,3 & 0,00453 \\
0,156 & 31,5 & 0,00315 \\
& 15,9 & 0,00159
\end{tabular}

Для ориентировки на краю спектра снимается узенькая полоска спектра ртути через специальное отверстие в диафрагме при удаленном ультрафиолетовом фильтре.

Оценка концентрации может производиться также по очередности появления полос различной интенсивности. При концентрациях в $0,001 \%$ появляется самая интенсивная полоса - 4045, при более высоких концентрациях появляется полоса 4281 и при концентрации 0,01\% появляются полосы 4100 и 4550.

Съемка спектров производится на позитивной кинопленке чувствительностью в $150^{\circ}$ по Х и Д. Проведенные съемки на высокочувствительной пленке в $5000^{\circ}$ особого преимущества не показали, так как более чувствительная пленка дает и более сильную вуаль. 
Стандартные и сравниваемые пробы необходимо снимать при одинаковых условиях и проявлять одновременно, чтобы исключить разницу в условиях проявления (концентрация проявителя, температура и т. д.).

Проба смолистых веществ, выделенных из дыма, загрязняющего атмосферный воздух, или продукты сухой перегонки сланца берутся в количестве $10-20$ мг. Взвешивание производится на торзионных весах путем накапывания со стеклянной палочки на прикрепленное к весам покровное стекло весом около 120 мг. Смола со стекла смывается в кювету посредством 0,25 куб. см дважды перегнанного бензола, с добавлением в кювету 2,25 куб. см нефлюоресцирующего вазелинового масла. После тщательного перемешивания вазелиновое масло окрашивается от смолы в желтоватый цвет. Без разведения смолу для анализа брать нельзя, так как входящие в состав смолы другие соединения своей флюоресценцией в близкой области могут затемнить флюоресценцию бензпирена.

Описанный метод спектрального флюоресцентного анализа был использован для исследования сланцевых масел из камерных печей и из опытной батареи, в которых был обнаружен бензпирен в количестве $0,01 \%$ и несколько больше, и сланцевых масел из генераторных печей, в которых в половине случаев были обнаружены следы бензпирена не более $0,001 \%$, а в другой половине проб бензпирен вовсе не был обнаружен. В смолистых веществах, выделенных из дыма атмосферного воздуха, были обнаружены следы бензпирена не более $0,001 \%$. Экстракты типографской краски из газет также содержат следы бензпирена, который может происходить из сажи, а также от масла, служащих для приготовления краски.

Результаты исследования используются для рационализации процессов производства, проведения мероприятий по гигиене труда и для обоснования санитарных требований к бездымному сжиганию топлива. 